\title{
Enigma y situación límite en un conjunto de cuentos folklóricos
}

\begin{abstract}
"Sabes el galardón de que te harás acreedor si consigues decirme una adivinanza que yo no conozca o no pueda adivinar, y el castigo que te espera si acierto el enigma que me propongas. En este último caso, eestás dispuesto a arrostrar la muerte?"
\end{abstract}

(del cuento La reina adivinadora, registrado por Ramón A. Laval).

\section{INTRODUCCIÓN}

1.1. El tema tratado en esta presentación ${ }^{1}$ está motivado por la observación directa de algunas constantes en la narrativa oral de la provincia de Osorno (sur de Chile). En este caso, la atención se focaliza en un grupo relativamente reducido de cuentos folklóricos, extraídos del conjunto mayor que conforma nuestro archivo. El conjunto seleccionado pertenece al grupo de narraciones que algunos autores han llamado "cuentos de adivinanzas". En Chile, los primeros cuentos de esta clase fueron recopilados por Rodolfo Lenz a comienzos de este siglo y es interesante verificar que, aun cuando no son muy abundantes en la narrativa folklórica, algunos de ellos han podido mantenerse hasta nuestros días.

Metodológicamente, se trata de encontrar el contenido estructural unitario de este conjunto y sus variantes internas, en perspectiva sincrónica; y, en segundo término, de establecer algunas relaciones mínimas de intertextualidad con referencia a elementos de la tradición oral chilena e hispano-europea; esto es, en perspectiva diacrónica ${ }^{2}$.

1.2. El título de este trabajo responde a la importante función que cumple la disyuntiva que conlleva la adivinanza o enigma como estructura integrada en el relato. A diferencia de lo que sucede con la adivinanza corriente, cuya actualización está enmarcada comúnmente en una situación

1 Este trabajo fue expuesto como ponencia en el I CONGRESO INTERNACIONAL DE NARRATIVA FOLKLÓRICA organizado por la Universidad Austral de Chile y llevado a efecto en la ciudad de Valdivia en octubre de 1993.

2 Cfr. Mihai PoP, "La poétique du conte populaire», Semiótica, II, núm. 2 (1970), pp. 117-127. 
lúdica, en estos cuentos la adivinanza o enigma forma parte de un contexto narrativo y puede llegar a afectar a un personaje llevándolo hasta una situación límite, que para él significa:

- esperanza/o clausura de una posibilidad;

- boda /o deseo frustrado;

- liberación / o condena;

- vida / o muerte.

El epígrafe que hemos elegido ilustra muy bien esta última y crucial alternativa, que, por cierto, aparece también, aunque formulada con otras palabras, en el contexto de varios de los cuentos que constituyen el corpus de nuestro estudio.

\section{ESTRUCTURA básica de eSTOS CUENTOS}

2.1. Llamamos estructura básica a la unidad de contenido subyacente en el conjunto de productos discursivos, que en este caso es el conjunto de los cuentos seleccionados. Esta estructura básica, por su simplicidad, ha sido retenida seguramente en forma fácil por la memoria y, como una matriz generativa, ha permitido la creación no sólo de varios cuentos parecidos, sino también ha facilitado su transmisión oral. Tal estructura puede asumir la configuración de una fórmula inicial que condensa los elementos centrales y comunes a todos los cuentos del conjunto y hace abstracción de las variantes y detalles:

UN DESTINADOR (A) PROPONE (IMPONE O PIDE) A UN DESTINATARIO (B) CONSTRUIR Y/O DESCIFRAR UNA ADIVINANZA O SITUACIÓN ENIGMÁTICA (X), CUYA SOLUCIÓN (O NO SOLUCIÓN) ES CONDICIÓN (Y) PARA LOGRAR UN OBJETIVO $(\boldsymbol{Z})$.

2.2. $\mathrm{Al}$ avanzar desde la estructura subyacente o profunda hasta el nivel de superficie, encontramos diversas variantes de la fórmula inicial plasmadas en las versiones concretas entregadas por los informantes y registradas por nosotros.

En síntesis:

1) En el cuento Adivinanza de Ana, un juez pide a un preso que le formule una adivinanza insoluble como condición para dejarlo en libertad. El preso la elabora a partir de una situación vivida. El objetivo se cumple. 
2) En Los pedidos del rey, un monarca plantea a un anciano (mediador) una situación enigmática, cuya solución es condición para casar con una de las hijas de éste. Resuelto el acertijo por la menor de ellas y consumada la boda, el rey impone una nueva prueba a su esposa para conservar la unión matrimonial.

3) En el cuento La adivinanza del tabür, un fanático apostador formula a un mozo una petición en forma enigmática para que los demás jugadores no se impongan (condición de ocultamiento) y de esa manera consiga el dinero que necesita.

4) En Los novios que no sabian su nombre, una novia plantea un enigma al novio (adivinarle el nombre), cuya solución es condición para que la boda se consume. Recíprocamente, el novio plantea un enigma similar a la novia. Ambos aciertan y la boda se realiza.

5) En El bijo que se enamoró de su madre, se revela inicialmente una relación edípica; pero, para evitar esta relación, el joven debe buscar una novia parecida a su madre. Cuando la encuentra, la pretendida impone al pretendiente la tarea de adivinarle el nombre como condición para que la boda se realice. El joven acierta y casa con la muchacha.

6) En El rey que tenía tres hijas casaderas, un rey asigna una tarea a un anciano. Basado en este hecho, impone a los pretendientes de la princesa la tarea de dar respuesta a una situación enigmática, cuya solución es requisito (o condición) para casar con ella. El anciano es el único que acierta, luego con él se consuma la boda. Pero él muere pronto y la princesa es conquistada - ahora fácilmente- por un príncipe. Se interpone una negra como rival, pero el príncipe le da muerte y casa con la princesa (nueva boda).

7) En El rey que tenía un cajón de plata, un monarca encierra a un adivino asignándole la tarea de resolver una situación enigmática: descubrir a los ladrones de un tesoro (cajón lleno de plata) y localizarlo. El adivino enfrenta la disyuntiva: probar su habilidad adivinatoria (condición) para recuperar su libertad, o morir; pero acierta de manera fortuita. El rey pone al adivino ante una nueva situación enigmática. El adivino de nuevo acierta de manera fortuita y recupera su libertad.

8) El cuento Grillo, el adivino del rey, con ligeras variantes, es igual al anterior.

9) En el Cuento con adivinanza, un rey propone a los padres de hijas casaderas una adivinanza, cuya solución (condición) permita encontrar a la mujer que sedujo al príncipe tonto. La adivinanza es elaborada con referencia a una situación prematrimonial vivida por la seductora y su pretendido. Lograda la solución, se consuma la boda.

10) En el cuento de Los tres hermanos y la adivinanza para el rey, un monarca pide a los pretendientes de su hija una adivinanza insoluble 
como condición para lograr la boda con ella. Frente a la disyuntiva de vida o muerte, un muchacho desvalido logra formular una compleja adivinanza a partir de las situaciones que vive en su trayecto hacia el reino. El rey no puede adivinar; luego el muchacho casa con la princesa.

11) El Cuento como adivinanza, con ligeras variantes, es igual al anterior.

\section{Clase de cuentos}

3.1. Estas narraciones pertenecen a la categoría de cuentos de adivinanzas o de enigmas. Ambas denominaciones, así como también la de acertijos, han sido empleadas indistintamente por muchos autores. Sin embargo, los traductores del libro Las formas simples de André Jolles ${ }^{3}$ prefieren la denominación de enigma a la de adivinanza para destacar precisamente su mayor complejidad con respecto a la adivinanza corriente; de modo que la adivinanza sería sólo la actualización del enigma. Jolles destaca también el carácter angustioso que presentaban los antiguos enigmas para quienes se enfrentaban a ellos ${ }^{4}$. Si se piensa en la adivinanza corriente actual, se puede advertir que ella configura una breve enunciación codificada e independiente. En estos once cuentos, en cambio, la adivinanza o el enigma forman parte de un contexto narrativo. Lo común es que la formulación verbal ingeniosa encubra un contenido que se presume sólo es conocido por el interrogador, quien, al exigir una respuesta, pone en juego también el ingenio y el saber del destinatario. La enunciación cifrada, o simplemente maliciosa, de un determinado contenido exige, por supuesto, demostración de destreza decodificadora por parte del destinatario. Además, en estos cuentos, la prueba de ingenio no es un simple acto recreativo o un pasatiempo; sino que comúnmente se plantea como dilema o encrucijada que puede afectar el destino de un personaje, en cuanto éste sea conducido hacia el mayor éxito aspirado o al fracaso más rotundo.

3.2. Por otra parte, estos relatos difieren en más de un rasgo de la categoría de cuentos maravillosos, como los estudiados por Propp, aunque ocasionalmente puedan encontrarse algunos vínculos con ellos. Pero el hecho de que la anécdota o historia narrada esté centrada en la formulación o desciframiento de una adivinanza o situación enigmática ya indica una diferencia importante. En la estructura más común del cuento tradi-

3 Nos referimos a Rosemarie Kempf Titze y Carlos Foresti SERrano. Vid. André JOLlES, Las formas simples (Santiago de Chile: Universitaria, 1972), p. 118.

4 A. Jolles, op. cit., p. 21. 
cional, el héroe buscador se contrata preferentemente para enfrentar y vencer físicamente al agresor: libra a una princesa raptada, repara la carencia inicial y es compensado con la boda. A lo más, el acto adivinatorio puede emerger en la puesta a prueba del héroe en la fase previa al matrimonio, o en secuencias anteriores: al encontrarse con el donante, al enfrentar al agresor o durante la persecución. Menos comunes son los cuentos que organizan su secuencia en torno a un héroe descifrador de adivinanzas o acertijos, como en $\mathrm{El}$ sastrecilllo valiente (o El sastrecillo listo) de la colección de los hermanos Grimm. Como en éste, los cuentos seleccionados para el presente estudio configuran un héroe que crea $\mathrm{o}$ resuelve acertijos por medio de su propio ingenio.

Propp señala que la prueba de las adivinanzas puede aparecer en un cuento maravilloso, entre las variadas "tareas difíciles" que se proponen al héroe (función XXV) ${ }^{5}$. En tales cuentos dicho protagonista puede vencer la dificultad únicamente con ayuda de un objeto mágico, o bien con ayuda de auxiliares premunidos de poderes mágicos o, por último, por medio de las cualidades sobrenaturales que le ha transmitido directamente el donante ${ }^{6}$. En general, en los cuentos de adivinanza o de enigma que conforman el conjunto aquí analizado el elemento mágico o maravilloso suele estar ausente. Tampoco el héroe recurre a un ayudante. Lo característico es que en estos cuentos el héroe resuelva por sí mismo la tarea de proponer una adivinanza difícil o un enigma insoluble o que decodifique una adivinanza o enigma complejo. Lo que se pone a prueba en estos cuentos es, pues, la habilidad natural del héroe para hacer frente a la situación difícil. Pero no se trata tampoco de habilidad o destreza física, sino únicamente de ingenio. De acuerdo con estos antecedentes, los cuentos de adivinanza o enigma tienden a constituir un grupo bastante definido y distinto con respecto al amplio grupo de los cuentos maravillosos, aunque ninguna clasificación de cuentos puede hacerse con precisión matemática, como bien observaba Aurelio M. Espinosa ${ }^{7}$. Si hubiera que atenerse a la categorización senalada por Thompson, los cuentos de la tradición oral que aquí se están analizando tendrían que entrar necesariamente en la clase denominada cuentos realistas de ingenio ${ }^{8}$.

5 Vid. Vladimir PROPP, Morfología del cuento, trad. por Lourdes Ortiz (de la ed. francesa de 1970) (Madrid: Fundamentos, 5. ${ }^{a}$ ed., 1981), p. 69.

6 Vid. función XIV: "El objeto mágico pasa a disposición del héroe", V. PrOPP, op. cit., p. 53.

7 Aurelio M. EsPINOSA, "La clasificación de los cuentos populares", Boletín de la Academia Española, XXI (1934), pp. 175-208. Vid. p. 197.

8 Stith THOmpson, El cuento folklórico, trad. de Angelina Lemmo (Caracas: Universidad Central de Venezuela, 1972), pp. 209-224. 


\section{EL DISCURSO ADIVINATORIO}

4.1. La adivinanza tradicional es un texto singularmente codificado dirigido a un receptor que debe efectuar un desciframiento específico de su mensaje. Esta acción decodificadora provoca un efecto lúdicro, sea por el hecho de acertar -o de no acertar- en su resolución.

En la terminología empleada por Jolles, la adivinanza es una "forma simple" opuesta al mito: el mito sería "una respuesta que contuvo una pregunta" y la adivinanza (o enigma) "una pregunta que exige respuesta" 9. Para Elli Köngäs Maranda, la adivinanza es una unidad discursiva integrada por dos partes: a) una imagen enigmática que comporta una pregunta y b) la respuesta a esa pregunta. Ambas partes están codificadas y han de ser actualizadas por el interrogador y el interrogado o adivinador, respectivamente ${ }^{10}$. Sin entrar en el análisis de los tres grados de complejidad que esta autora distingue (adivinanzas simples, compuestas y encadenadas), podemos decir que estos breves discursos destinados a ser repetidos tienen frecuentemente forma externa de estrofas autónomas, de verso medido, y a menudo con rima en los versos pares. Por otra parte, la imagen puede estar enunciada en primera persona o en tercera, independientemente de quien la actualice. Además, el contenido cifrado de la adivinanza puede descansar únicamente en la analogía de la imagen verbal con el referente, como en los siguientes ejemplos: 1) "Blanca soy, / del agua nací; / pobres y ricos / comen de mí" (la sal). 2) "Fui al mercado, / compré una bella, / llegué a mi casa / y lloré con ella” (la cebolla). O bien, la analogía puede estar dada sólo en el nivel del significante, como en los siguientes ejemplos: 3) “En una esquina había: ¿qué sería ?, ¿qué será?” (una quesería). 4) "Ave soy, pero no vuelo, / mi nombre es cosa muy llana, / soy una pobre serrana, / hija de un hijo del suelo" (la avellana).

Las adivinanzas tipo - como las transcritas precedentemente- no se vinculan con un contexto del cual habrían de formar parte de una manera residual o estructurada. Mucho menos puede esperarse referencias a su creación o que su exégesis exceda la extensión de su palabra clave (la sal, la cebolla, una quesería, la avellana). En cambio, en los cuentos que aquí se presentan, las adivinanzas, o las situaciones enigmáticas simplemente descritas y no estructuradas en una fórmula, participan de un contexto narrativo. Es probable también que muchas de las adivinanzas

9 A. JOlles, op. cit., p. 120.

10 Elli KÖNGäS MARANDA, "The logic of Riddles", en Pierre MARANDA and Elli KÖNGäS MARANDA, Structural Analysis of Oral Tradition (Philadelphia: University of Pennsylvania, 1971), pp. 189-232. 
corrientes sean micro-textos o discursos condensados de un ciclo narrativo originario del cual se habrían desprendido por tradición, pero no hay elementos suficientes como para sostener esta hipótesis.

Lo notorio de los textos que aquí se describen es que narran el acto de construir la adivinanza, acertijo o enigma (para un juez, un rey, el amado o la amada) tanto como el proceso adivinatorio por parte de quien es emplazado como adivinador (un "leso", un padre, un anciano) o es reconocido como adivino de profesión, como es el caso de Juan Grillo, a quien se le exige dar prueba de tal condición. Además, si la norma indica obviamente que se formule la adivinanza o enigma a quien no haya participado en su creación, el cuento El rey que tenía tres hijas casaderas muestra cómo se transgrede esta exigencia, cuando un rey parece suponer que el estacador de la piel del piojo ha olvidado el incidente.

A manera de hipótesis, puede sostenerse que la adivinanza tradicional se rige por un código colectivo que hace innecesario cualquier macro relato o acto exegético complementario. Por el contrario, cuando la adivinanza deriva de un sujeto que codifica un trance específico protagonizado por él, se torna hermética y singular, lo que exige referir el relato básico de la historia que la ha originado. En la Adivinanza de Ana sólo el padre conoce la ayuda que le dio la hija y puede cifrarla en una especie de estrofa; en Los tres hermanos y la adivinanza para el rey y su variante Cuento como adivinanza, sólo el "leso" sabe los percances que le han ocurrido en el camino, materia referencial para la creación de sus adivinanzas.

4.2. En síntesis, estos relatos refieren tanto la historia de la codificación de una adivinanza o enigma como el proceso de su decodificación o desciframiento (la adivinanza que un rey formula para saber quién ha seducido a su hijo "leso"; la que se propone entre novios para adivinarse los nombres; la situación enigmática elaborada por un rey para proponerla a los pretendientes de la princesa, etc.). En este punto conviene advertir que las adivinanzas o situaciones enigmáticas así presentadas en los cuentos, superan la mera condición de acertijos de entretenimiento. Adquieren el rango propio del dilema, caracterizado por presentar al adversario una argumentación destinada a confundirlo, cualquiera que sea la respuesta que elija, y lo deja a merced de una situación límite en la cual arriesga la vida, la libertad, el amor, el crédito o el prestigio. De ahí que los relatos que aquí se analizan como cuentos de adivinanza convenga llamarlos, tal vez con más propiedad, cuentos de enigma, puesto que ocultan ostensiblemente la respuesta — a la manera de un intríngulis_- más allá del simple juego de palabras, y además por la incidencia directa que tiene el acto adivinatorio en el destino de un personaje. 
La descripción precedente conduce a distinguir tres modalidades del discurso adivinatorio en este conjunto de cuentos:

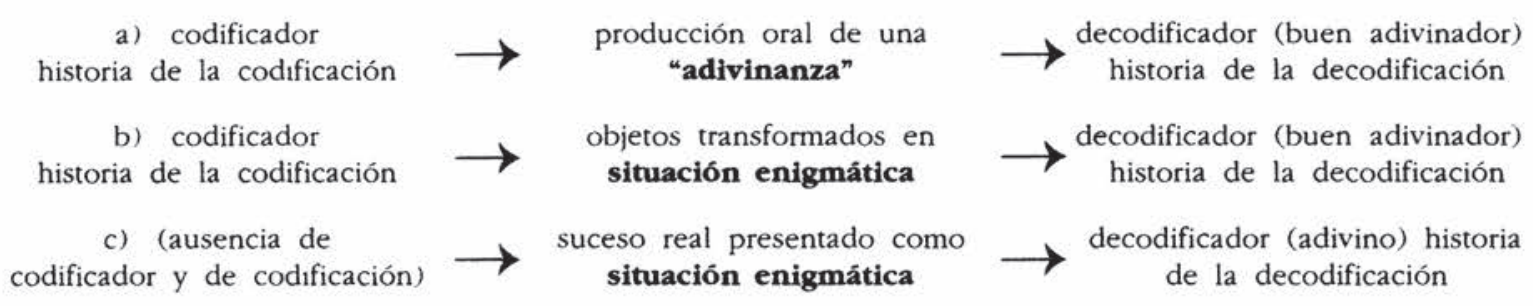

Las instancias señaladas en cada una de estas modalidades pueden variar en cuanto al grado de atención exigido por el contexto. Algunos cuentos acentúan la instancia decodificadora; otros acentúan la instancia codificadora; pero en otros, como en el caso de la tercera modalidad, la instancia codificadora puede estar ausente, con lo cual la situación enigmática se torna mucho más misteriosa que en los demás casos y exige recurrir a un verdadero adivino.

\section{LA PREgunTA. HiSTORIA DE LA CREACIÓN DE ADIVINANZAS O ENIGMAS}

5.1. El cuento Adivinanza de Ana sugiere el carácter finito del adivinancero, pues todas las adivinanzas estarían registradas en un texto patrimonio de todos ("en los libros qué adivinanzas no hay, pues") y, en particular, serían patrimonio de un individuo superior en sabiduría (un juez, el rey), quien, por tal razón, puede ejercer el poder tanto como el saber. De ahí que constantemente someten a sus adversarios imponiéndoles en forma arbitraria pruebas y acertijos que deben ser respondidos. De lo contrario, el rival se expone a una condena o a la pena de muerte. "No ve que el rey, cuando quería comer gente, antes, ya comenzaban a hacer cualquier cosa por mandamiento", afirma al respecto el narrador de Cuento como adivinanza. Este título explicita, además, que la adivinanza puede constituir perfectamente todo un relato y, a la vez, da cuenta del proceso de crear adivinanzas.

De ahí que en algunos de estos cuentos se exija, justamente, construir nuevas adivinanzas, confiándose en que sería imposible lograrlo - ya que todas son conocidas por el rey o por alguien de rango equivalente (como un juez) - o porque se responda a la necesidad de aumentar el libro de las adivinanzas.

Cualquiera sea la motivación, lo cierto es que toda adivinanza original lleva consigo no sólo su respuesta, sino que igualmente implica dar a conocer cómo fue construida, puesto que no son fruto de la tradición colectiva sino de una elaboración personal. Por ejemplo, en Adivinanza 
de Ana, sólo la hija y su padre saben lo ocurrido en la cárcel; en su camino hacia el reino, sólo el "leso" ha visto las muertes que se han producido a su alrededor, sin sospechar que el veneno estaba destinado a él, según conocemos en Los tres hermanos y la adivinanza para el rey y en su equivalente Cuento como adivinanza.

Obsérvese que, en una primera aproximación, un título como Adivinanza de Ana remite a la autora del acertijo, pero lo cierto es que el proceso de su enunciación corresponde al padre. "Ése es el mismo hecho de él, las mismas exper(i)encias que él estaba haciendo. Entonces ésas las sacó de adivinanza. La sacó en esa forma”, concluye el narrador, quien, no conforme con repetir la adivinanza, ha creído conveniente explicar su origen y la importancia del discurso adivinatorio, pues no en vano su autor con esta clave obtuvo la libertad.

5.2. La producción de un discurso adivinatorio establece una estructura semántica cuyo eje es "vencer a otro mediante el saber" o "probar la destreza intelectual del otro". La victoria que se obtenga objetivará el bien deseado "como apetencia de reconocimiento y ascenso social". Y en esta competencia los "lesos" pueden perfectamente demostrar que son cuerdos, y los enamorados pueden reconocerse como tales.

Los tres hermanos y la adivinanza para el rey y su variante Cuento como adivinanza son buenos ejemplos al respecto. Si inventar una adivinanza es difícil para un cuerdo, será imposible para un "leso" a quien por una falsa compasión le preparan un envenenamiento. Mas, contradictoriamente, el protagonista elabora ("estudia") lúcidamente cada una de las peripecias vividas, concluyendo que tiene "la adivinanza por sus manos". Según el narrador, éste es un "cuento o adivinanza" que oculta su respuesta con tal grado de complejidad y hermetismo que el rey se da por vencido.

Por lo mismo, es digno de advertir que la adivinanza codificada en las versiones de este cuento supera en dificultad a las que elaboran cuerdos enamorados como es el caso de Los novios que no sabian su nombre y El hijo que se enamoró de su madre. El análisis comparativo del modo de enunciación de estos relatos muestra que uno de los principios que rigen la construcción del texto de la adivinanza es el recurso de la relación analógica. Su base puede ser denotativa y conceptual, propia de procesos ideográficos y simbólicos, como en el nombre de Florentina (flor + tina), o de homofonía sintáctica en Ignacio (y nació) y Elena Mora (el enamorado). Para el hijo "leso", "lo duro" y "lo blando", actúan analógicamente también frente a "camino de tierra" y "río", respectivamente; pero en este caso el codificador "voluntario-involuntario" de la adivinanza alcanza un mayor grado de enunciación connotativa en expresiones como "apunté el 
(sic) que vi, maté el que no vi y comí carne no nacida, con palabras sagradas", lo que supera el simple juego homofónico como el dado en las adivinanzas anteriormente referidas. Un grado similar de elaboración está presente en la versión cifrada de la seducción del hijo "leso" del rey ("palomo") por parte de una atrevida doncella ("paloma") que se introduce subrepticiamente en la habitación palaciega ("palomar").

Los relatos aludidos muestran perfectamente las relaciones intratextuales entre la adivinanza como forma condensada de una historia y el cuento como discurso de primer grado que la contiene: el "leso" luego de atender a los inexplicables hechos que se originan cuando no se come el huevo o la tortilla envenenados, llega donde el rey y le cuenta "solamente la adivinanza", dice el narrador. En otro cuento el rey tiene claras señales de que alguien ha seducido a su hijo "leso" y codifica este hecho en la adivinanza que propone a las mujeres para identificar a la seductora.

\section{LA RESPUESTA. ADIVINACIÓN DE UNA HISTORIA}

6.1. La instancia de enunciación de la adivinanza corriente es de preferencia una actuación lúdica en la cual se formula una pregunta que exige una respuesta, conocida de antemano por el destinador. En el caso de la adivinanza enmarcada en estos cuentos o de la situación enigmática, creada o dada simplemente dentro de los hechos narrados, la decodificación o respuesta conduce necesariamente a un premio (boda, libertad, riqueza) o a un castigo (muerte, descrédito). Por lo mismo, el codificador de adivinanzas o enigmas puede ser descrito como un manipulador: su meta es demostrar su saber frente a la ignorancia del otro. No obstante, esta sabiduría puede ser refutada si se demuestra que el rey es incapaz de actuar como árbitro en una contienda. Tal contratextualidad adivinatoria y actancial es ampliamente desarrollada en el cuento Los pedidos del rey. En dicho relato, los acertijos adquieren el carácter de un dilema o intríngulis de primer grado: un padre debe presentar a sus hijas "preña(d)as y doncellas; calza(d)as y descalzas; a pie y a caballo; peina(d)as y sin peinarse". La hija menor se guía por las pautas analógicas y denotativas que hemos enunciado y acierta con la respuesta. A su vez, es capaz de formular acertijos (pide "harina tostada con nieve") que el rey no resuelve. Por esta razón, el rey casa con ella con el objeto de conjurar esta cualidad adivinatoria: prohíbe a su mujer participar en cualquier acertijo que ponga en riesgo su sabiduría. Sin embargo, el arbitraje se presenta cuando el rey debe decidir un dilema que le proponen, y que contradice la norma de la relación analógica y conceptual: "que tras un 
caballo trote un potrillo no significa que el caballo lo haya parido". La esposa advierte el falso razonamiento y, tal como había ayudado anteriormente a su padre, ahora permite que el esposo corrija su decisión, haciéndole ver que: "del grano tostado no pueden nacer frutos".

En este diálogo de adivinanzas y contra-adivinanzas, la mujer asume un rol activo, según se refiere en Cuento con adivinanza. Un rey sospecha que su hijo "leso" ha sido seducido por una joven y que la seductora ha quedado embarazada. Para descubrirla, difunde una adivinanza: "Estaba el palomo en su palomar./ Vino la paloma/, lo vino a tantear./ La vieron salir, pero no entrar..." La joven responde enviando a su padre a venderle al rey un canasto de flores en el cual oculta al recién nacido. El anciano debía pregonar: "iQuién compra flores, mal de amores!"; y debía responder a la curiosidad del rey únicamente diciendo: "Lo que llevó lo mandó a dejar".

Que la mujer sea objeto de destinación por parte del mandatario, se discute en El rey que tenía tres hijas casaderas. En este caso, el acertijo sobre la piel del piojo es tan singular que el rey se ve obligado a proponerlo a quien ayudó a construirlo. El hecho contraviene lo propio del acto adivinatorio, lo que se acentúa cuando la hija, obligada a casarse con un anciano, se libra del marido al atravesar un río. Posteriormente, el relato sigue el curso normal de una historia de boda entre iguales en edad y nivel social.

6.2. Toda adivinanza supone el intercambio de la pregunta y de la respuesta como acto presencial entre un emisor y un receptor, pero el cuento La adivinanza del tabúr presenta una contradicción a esta norma. Un jugador pide a su mozo que venda "el entrepiernas", "el mete que saca" y "el dale que dale", sin que sus rivales sepan que se trata del "caballo", el "freno" y las "espuelas", respectivamente. La fórmula enigmática tiene aquí la función de ocultamiento. El contenido decodificado sólo es dado por el narrador, desde la extradiégesis, para sus auditores y su construcción se rige conforme a la norma analógica, que en este caso adquiere un tono jocoso por su aparente ambigüedad.

Finalmente, las versiones del cuento relativo a Juan Grillo conforman el relato más enigmático del conjunto. Un suceso que afecta al rey tiene carácter misterioso. El rey ha sido víctima de un robo y desconoce el nombre de los autores y el destino de las especies. Por ello recurre a un adivino, quien debe investigar los hechos, a la manera de un caso policial, encontrar a los culpables y recuperar el tesoro, puesto que no se trata de un vidente, aunque Juan Grillo pretende serlo, pues se define como "adivino de profesión y de cartel”, cuando en realidad no lo es. El rey lo pone a prueba y lo amenaza de muerte si no resuelve el misterio y sólo por 
azar Juan Grillo descubre a los ladrones. El enigma adopta entonces la forma del acertijo, conforme a lo ya descrito: los criados del rey, que eran sospechosos del robo, debieron llevar alimentos durante tres días a Juan Grillo. Este contaba en voz alta uno a uno los días que tenía para adivinar, lo que fue interpretado por los ladrones como su descubrimiento, por lo cual confiesan e indican dónde ocultan todo. El acierto del adivino se debe, pues, a un hecho fortuito y no a su capacidad adivinatoria. Luego el rey oculta un "grillo" entre sus manos y con él lo somete a una segunda prueba de adivinación. Juan Grillo acierta nuevamente de manera fortuita cuando, ante la situación apremiante, exclama: "iEn qué apretura te hallas, pobre Grillo!". Logra su libertad, pero el cuento revela la impostura y el descrédito de quien se considera adivino de profesión.

\section{ANTECEDENTES HISTÓRICOS}

\subsection{Adivinanza o enigma en textos de la tradición bispano-europea}

7.1.1. De la oralidad a la literatura escrita o de ésta a la oralidad, siempre será muy difícil establecer cómo se han generado algunos temas y motivos recurrentes en el folklore. Desde el Medio Oriente se han difundido por el mundo occidental los acertijos bíblicos que la reina de Saba propone al rey Salomón y que éste resuelve correctamente. Algunos de ellos se han introducido en el folklore (Motivo H 540.2.1), según Thompson ${ }^{11}$. Pero hay otros ejemplos, de la tradición occidental, que hunden sus raíces en la literatura de la antigüedad clásica. Entonces se practicaban las llamadas artes adivinatorias y hay constancia de su temprano tratamiento literario. Propp, en su libro Edipo a la luz del folklore ${ }^{12}$, ha estudiado los vínculos del ciclo edípico con tradiciones antiguas y modernas del folklore europeo. En la tragedia, Sófocles caracteriza a Edipo como un personaje "diestro en desembrollar enigmas". Y es esta destreza precisamente la fuerza interior que le permite vencer el desafío de la Esfinge, monstruo que daba muerte a los tebanos que no lograban descifrar los enigmas que les formulaba. Edipo libera al pueblo de Cadmo del peligro de la Esfinge y obtiene la mano de la reina viuda Yocasta, sin saber que ésta es su propia madre.

Hay - le dice la Esfinge - un ser que anda a cuatro pies, a tres y a dos, y precisamente es tanto más tardo y lento cuantos más son los pies en que se apoya.

11 S. THOMPSON, op. cit., p. 350.

12 Vladimir PRopp, Edipo a la luz del folklore, trad. del italiano por C. Caro López (Madrid: Fundamentos, 2. ${ }^{\mathrm{a}}$ ed., 1982). 
Oye, aunque no lo quieras —contestó Edipo—, mi voz y tu perdición: es el hombre; de niño se arrastra con las cuatro extremidades, y de viejo busca un tercer pie en el bastón en que se apoya, encorvado bajo el peso de los años ${ }^{13}$.

En Edipo Rey no sólo el héroe es descifrador de enigmas. Otro personaje, el viejo Teresias, adivino ciego de Cadmo, es quien transmite en forma enigmática a Edipo el sentido de la profecía oracular que terminará por aniquilarlo:

(...) el hombre que hace tanto tiempo y con tantas amenazas buscas, decantando el asesinato de Layo, ese hombre está aquí, y es, a lo que se dice, un extranjero domiciliado entre nosotros; pero pronto se hallará su verdadero natural tebano, y a fe que no se alegrará con el descubrimiento. Porque ciego el que ahora ve y mendigo el que es ahora opulento, saldrá a recorrer tierras extrañas y a tantearlas con su bastón de ciego. Y aparecerá que es para sus hijos hermano a un mismo tiempo y padre; y para la mujer que le dio vida, hijo a la par y marido, y para su padre, cónyuge de su mujer y matador de él. Y ahora vete, piensa todo eso, y si en algo me sacas mentiroso, entonces di que no entiendo de profecías ${ }^{14}$.

7.1.2. Estos antiguos enigmas muestran precisamente el carácter angustioso de que habla Jolles, pues aparecen ligados fuertemente a los avatares del destino humano. Pero también aparecen tempranamente las adivinanzas, concebidas como ejercicios más libres del ingenio. María Rosa Lida verifica que motivos de esta clase se encuentran en la literatura popular del Viejo Mundo, de varias épocas, y que muchos de ellos siguen vigentes en la narración folklórica de los países americanos. Señala que, como en la griega, también en la tradición latina se encuentran algunas muestras de su tratamiento literario. Nos recuerda que Cicerón escribió un texto llamado De adivinatione y que la Égloga tercera de Virgilio "termina con un certamen de adivinanzas" ${ }^{15}$. Este ejemplo habría de ser imitado más tarde por varios autores españoles de novelas pastoriles, como Sannazaro, Montemayor, Montalvo, Gil Polo, e incluso aparecerá en obras de Cervantes y Lope de Vega. En el "Quijote" de Avellaneda, cap. XXIV, Sancho propone una adivinanza de parecido, del tipo que Ramírez de Arellano ha llamado "Animal del otro sexo": "¿Qué es cosa y cosa que parece burro en pelo, cabeza, orejas, dientes, cola, manos y pies, y lo que más es, hasta en la voz, y realmente no lo es? y no me supieron jamás

13 SÓFOCles, Tragedias completas (Madrid: Aguilar, 4. ${ }^{3}$ ed. en español, 1962), pp. 21-22.

14 SÓFOCles, op. cit., pp. 47-48.

15 María Rosa LIDA, "El cuento popular hispanoamericano y la literatura", en El cuento popular y otros ensayos (Buenos Aires: Losada, 1976), pp. 9-80; vid. p. 27. 
decir que era la burra" ${ }^{16}$. Y Lope de Vega en La doncella Teodor recrea un cuento de Las mil y una noches que se repite después en la novela picaresca (atribuida a Francisco López de Úbeda) La pícara Justina, II, 1, "un certamen en que la sabia heroína contesta satisfactoriamente las preguntas de cosmología aristotélica y los enigmas de varia ciencia que le formulan sus examinadores" ${ }^{17}$. Y, a propósito de Las mil y una noches, poderoso producto de la cultura arábiga cuya difusión en el mundo hispánico es indudable, habría que agregar otro caso típico de planteamiento y resolución de un enigma: el que se presenta en la Historia singular del príncipe Almás. Aquí el héroe, ante la disyuntiva de acertar y obtener la mano de la princesa, o morir decapitado, supera todos los obstáculos para encontrar la clave de la pregunta formulada por la princesa Mohra: "QQué clase de relación existe entre Pina y Ciprés?”. El príncipe Almás llega a la ciudad de Uakak, descubre la clave del enigma en la historia personal del rey Ciprés y su esposa Piña y luego vuelve al país de Babil, da respuesta irrevocable al enigma planteado por la princesa, obtiene su mano y regresa a su patria no sólo con ella, sino también con un cortejo de cuatro esposas más (noches 872 a 885$)^{18}$. En otro cuento de la misma obra, la Historia del bijo del rey y la soberbia princesa (noches 936 a 939) ${ }^{19}$, el hijo de un rey que ha caído en la pobreza es el centésimo postulante a la boda con una princesa que plantea preguntas enigmáticas a sus pretendientes. Los noventa y nueve anteriores han sido decapitados. El héroe no sólo contesta satisfactoriamente cada uno de los variados y capciosos acertijos, sino que, además, le propone un enunciado enigmático, que aquélla no puede responder, porque se refiere a circunstancias personales. El cuento concluye con el siguiente tópico: "Y así fue cómo el joven aquel, hijo del rey pobre y de la reina pobre, llegó a ser el esposo de la princesa de los enigmas y las cuestiones" ${ }^{20}$.

Estos cuantos ejemplos demuestran que los enigmas enmarcados en textos escritos y orales, hunden sus raíces en centenarias tradiciones literarias orientales y occidentales. Conocido es también el cuento $E l$ sastrecillo valiente (o El sastrecillo listo) de la colección de los hermanos Grimm, cuya historia -en su primera parte- se estructura en torno a un héroe que, pese a ser el menos talentoso de tres hermanos, logra descifrar

\footnotetext{
16 M. R. LIDA, op. cit., p. 52.

17 M. R. LIDA, op. cit., p. 53.

18 Citamos El libro de las mil y una noches por la edición de Rafael Cansinos Assens (México: Aguilar, 1966), 3 tomos. Vid. en este caso el tomo III, pp. 1027-1067.

19 Ibid., pp. 1237-1245.

20 Ibid., p. 1245.
} 
el acertijo planteado por una princesa. En la segunda parte del cuento, el héroe es sometido a una prueba de fortaleza física y psíquica (pasar una noche encerrado con un oso). El héroe vence tres situaciones de peligro ante la fiera exclusivamente con ingenio. Así el más desvalido logra la boda con la princesa y se sobrepone a sus propias carencias.

7.1.3. Dentro de la tradición hispano-europea más directa, podría ser muy interesante revisar la Colección de enigmas y adivinanzas de don Antonio Machado y Alvarez (Demófilo), pero de esta obra sólo tenemos la referencia de Lenz ${ }^{21}$. En cambio, disponemos de dos notables relatos de enigma consignados por don Ramón Menéndez Pidal en su Antología de cuentos de la literatura universal ${ }^{22}$ : un cuento de un autor renacentista italiano y otro de la tradición oral española. Ambos desarrollan el mismo motivo, pero con variantes. El primero, de Franco Sacchetti (m. 1400), se titula El caballero, el abad y el molinero. Un gran señor de Milán plantea al abad un enigma cuya solución permita a este último liberarse de la sanción que merece por una falta cometida. "Te perdono - le dice- los cuatro mil florines si me explicas las cuatro cosas siguientes: qué distancia hay de aquí al cielo; cuánta agua contiene el mar; qué es lo que se hace en el infierno, y cuánto vale mi persona". El abad muy preocupado pide la colaboración de un molinero que se muestra más diestro. Éste toma los hábitos del abad y con gran destreza elabora respuestas muy ingeniosas e irrefutables para cada una de las cuatro partes del enigma. El señor, sorprendido por el ingenio de las respuestas, descubre la suplantación y dictamina que "de por vida fuese el abad molinero y el molinero abad" ${ }^{23}$. Se advierte, pues, que el hecho de decodificar un enigma conduce a un ascenso social; la impostura, en cambio, es castigada.

En el segundo cuento, que lleva por título precisamente Los enigmas ${ }^{24}$, es un obispo quien, para verificar si su abad está o no a la altura de su cargo, le plantea tres preguntas enigmáticas que debe responder en un plazo perentorio: "La primera es ésta: si yo quisiera dar la vuelta al mundo, ¿cuánto tiempo tardaría? La segunda: si yo quisiera venderme, ¿cuánto valdría? Y la tercera: ¿qué cosa pienso yo y no es verdad?" En este cuento es el frailecillo que guarda las ovejas quien contesta por el abad. A la primera pregunta responde: "Según la prisa con que caminéis. Si camináis

21 Rodolfo LENZ, "Cuentos de adivinanzas corrientes en Chile", Revista de Folklore Chileno, II, pp. 337-383; III, pp. 267-309 (1912-1914). Vid. III, p. 273.

22 Ramón MENÉndez PIDAl, Antología de cuentos de la literatura universal (reimpresión de la $3 .^{\mathrm{a}}$ ed. de 1955) (Madrid: Labor, 1958).

23 R. MENÉNDEZ PIDAL, op. cit., pp. 350-351.

24 R. MENÉNDEZ PIDAL, op. cit., pp. 968-969. 
tan de prisa como el sol, tardaréis solamente veinticuatro horas". A la segunda pregunta, la respuesta es: "Quince dineros (...) Porque Jesucristo Nuestro Señor era Dios y valió treinta, y es justo que Su Ilustrísima valga sólo la mitad que Jesucristo Nuestro Señor". Y a la tercera: "Pues Su Ilustrísima piensa que yo soy el abad del monasterio y soy el fraile que guarda los rebaños". El dictamen del obispo no se hace esperar: "Id ahora mismo al convento, entregadle los rebaños al abad para que los apaciente y quedaos vos de abad".

Pero éstos no son cuentos aislados. Ambos se pueden identificar en el índice internacional con el Tipo 922, en torno al cual se han reunido numerosas versiones folklóricas, conocidas principalmente con el nombre de El emperador y el abad o, en el mundo anglo-sajón, a través de la balada de El Rey Juan y el Obispo. Según Thompson, el investigador Walter Anderson ha estudiado cerca de seiscientas versiones, orales y escritas, de este tipo de cuento, cuya forma original - supone- habría surgido hacia el siglo VII después de Cristo en alguna comunidad judía del Cercano Oriente, posiblemente Egipto ${ }^{25}$.

Los ejemplos citados, por lo general participan de los mismos elementos estructurales de los cuentos de adivinanzas o de enigmas recogidos de la tradición oral actual. Se puede decir que difieren únicamente en elementos microestructurales que singularizan cada uno de los productos verbales como unidades narrativas autónomas.

\subsection{Tipología y filiación de los cuentos de adivinanzas o enigmas registrados en Osorno}

Vistos estos antecedentes, no será extraño encontrar, en el material textual que ahora nos preocupa, viejos temas o motivos transmitidos y recreados por una larga tradición que hunde sus raíces en seculares textos, escritos u orales, del viejo continente.

1) El cuento titulado Adivinanza de Ana corresponde al Tipo 927 del indice internacional de Aarne-Thompson, pues en éste "la persona acusada quedará libre si le puede proponer al juez un acertijo que no pueda resolver" ${ }^{26}$. El acertijo es elaborado por el presidiario basado en su propia experiencia de haber sido alimentado a través de las rejas de la cárcel nada menos y nada más que con la leche de su propia hija. En el cuento oral de Osorno, la adivinanza aparece codificada en los siguientes términos:

\footnotetext{
25 S. THOMPSON, op. cit., pp. 220-221.

26 S. THOMPSON, op. cit., p. 221 ; cfr. p. 622.
} 
"Ana fue hija, / Ana fue madre, / mantuvo hijo ajeno, / marido de su madre". Este cuento no es extraño en la tradición oral chilena. Es así como Yolando Pino ${ }^{27}$ consigna cuatro versiones similares que contienen curiosas variantes de esta fórmula enigmática, puestas ahora en boca de la hija del preso. Las más similares son: "Andaña jue padre, / Andaña jue hijo. / Crié hijo ajeno, / marío 'e mi madre" y "Yo de Juan soy hija / y ahora soy madre, / crío a hijo ajeno / y marido de mi madre" 28.

La antigüedad del tema ya fue destacada por Lenz, quien -basado sobre todo en los estudios de Lehmann-Nitsche sobre versiones argentinas - dice que se han registrado numerosas variantes de este cuento en diversos países de Europa. Y sobre todo es imprescindible citar la siguiente observación : "Pitrè menciona que el tema ha sido ya tratado por Plinio i otros autores de la antigüedad clásica, que se encuentra representado en una pintura de Pompeya" ${ }^{29}$. Es decir, la antigüedad del motivo está corroborada por la escritura y por la imaginería. El mismo Yolando Pino reproduce la imagen de una escultura que se encuentra en el vestíbulo de la Biblioteca Nacional de Madrid y que ilustra muy bien el motivo de la mujer que ocultamente ha alimentado con su leche al padre condenado a morir de hambre, motivo desarrollado en los cuentos núms. 140-143 de su colección ${ }^{30}$. Y María Rosa Lida aduce más información sobre las raíces y ramas de su contenido: "La venerable antigüedad de este motivo se acredita por el hecho de haber servido de leyenda explicativa para la fundación del templo de la Piedad filial (erigido en Roma en el segundo siglo antes de Cristo)", según los testimonios de Tito Livio, Plinio, Valerio Máximo y Solino, todos autores latinos muy leídos en la España medieval. $\mathrm{Y}$ agrega que, modernamente, "el tema inspiró varios cuadros de Crespi, Guido Reni, el Parmesano, Honthorst y Bachelier" ${ }^{31}$.

2) El cuento Los pedidos del rey pertenece al Tipo 875 del índice internacional. El cuento que Aarne-Thompson tipifican en la historia de La campesina ingeniosa, puede resumirse así: La hija de un campesino llega a ser esposa de un rey después de resolver las pruebas de ingenio que le ha dado. El rey se enoja con ella y la despide, pero, finalmente, al permitirle llevar el bien más querido, ella opta por el esposo ${ }^{32}$. De este

27 Yolando PINO SAAVEDRA, Cuentos folklóricos de Chile (Santiago de Chile: Universitaria, t. I, 1960; t. II, 1961; t. III, 1963).

28 Y. PINO SAAVEDRA, op. cit., t. II, pp. 276-277.

29 R. LENZ, op. cit., III, p. 282.

30 Y. PINO SAAVEDRA, op. cit., t. II , pp. 276-277.

31 M. R. LIDA, op. cit., pp. 66-67.

32 Cfr. S. THOMPSON, op. cit., p. 217. 
cuento hay varios aspectos coincidentes con las versiones de La niña que riega la albahaca, compiladas por Lenz. Pero este mismo investigador cita una versión mucho más completa registrada por los hermanos Grimm con el título de La astuta hija de campesino (núm. 94) y asimismo una versión muy reducida registrada en Portugal por Theophilo Braga ${ }^{33}$. Por su parte, María Rosa Lida menciona y resume el relato De una joven campesina que llegó a ser gran señora, clara versión del mismo cuento, publicado por Susana Strowska en sus Leyendas polacas ${ }^{34}$. Por último, también corresponden al Tipo 875 ( $\mathrm{y}$ al 879) las tres versiones que registra para nuestro país Pino Saavedra con el título de La mata de albahaca (cuentos núms. 124, 125 y 126 de su colección). Todos estos testimonios corroboran la difusión internacional de este cuento de enigma. Una variante antigua del mismo cuento es seguramente el relato de Las mil y una noches titulado Historia de la bija del garbancero (noches 777 y 778) ${ }^{35}$, en el cual el hijo de un sultán somete a prueba a un vendedor de garbanzos tostados. La prueba consiste en que éste debe presentarse ante él vestido y desnudo al mismo tiempo, riendo y llorando a la vez y montado a caballo y a pie. Por consejos de la menor de sus tres hijas, se presenta envuelto en una red, se frota los ojos con una cebolla para llorar y reír al mismo tiempo y va montado en un borriquillo de baja alzada que le permite tocar el suelo con los pies. Luego sucede un episodio muy diferente, pero de todas maneras el cuento termina con la boda de un hombre rico con una plebeya.

La versión recogida en Osorno se ajusta bastante al esquema típico indicado por Thompson, pero hay una variante fundamental: mientras en el cuento tipo el rey pide a la campesina que se presente ante él "ni desnuda ni vestida, ni de noche ni de día, ni sucia ni limpia" y ella llega "envuelta en un trapo, o al anochecer, o con sólo un lado de su cuerpo lavado", en la versión osornina el rey pide a un anciano inquilino que comparezca en palacio con sus tres hijas, encintas y doncellas, calzadas y descalzas, de a pie y de a caballo, peinadas y despeinadas. La menor de las hermanas es quien encuentra la forma más adecuada para resolver el acertijo: confecciona para sí y para sus hermanas disfraces que simulan embarazo, acuerda con ellas calzar sólo un zapato, improvisa caballos de varillas y todas se presentan peinadas sólo por un lado.

Otro aspecto importante de la versión osornina es la actualización de algunos motivos tradicionales. Uno de ellos es el del deseo o "tarea

33 R. LENZ, op. cit., III, pp. 270-271.

34 (Madrid: Revista de Occidente, 1928), ref. en M. R. LIDA, op. cit, p. 74.

35 El libro de las mil y una noches, ed. cit., t. III, pp. 721-727. 
imposible" (Motivo H 1010): la heroína pide en la corte que se le prepare "harina tosta(d)a con nieve", como en algunos cuentos europeos en que el deseo es "conseguir fresas en invierno" (Motivo H 1023). Otro es el de la reductio ad absurdum (Motivo J 1191): cuando el rey resuelve injustamente una disputa sobre la posesión de un potrillo, la esposa aconseja al dueño recurrir a un hecho absurdo para demostrar al rey que más absurda aún ha sido su presunta justicia ${ }^{36}$. Un tercer motivo es el de "la más querida posesión de la mujer asediada" (Motivo J 1545. 4.1): como en una de las versiones de Pino Saavedra ${ }^{37}$, cuando el rey va a arrojar de la casa a la esposa y le ofrece que se lleve lo que más estima, ella le toma la bragueta y luego se reconcilian.

3) El cuento La adivinanza del tabúr es muy simple. La formulación enigmática tiene aquí una finalidad de ocultamiento. El tahúr, que tiene mala suerte en el juego, no quiere que los demás se enteren de su propósito de vender lo poco que le queda para obtener dinero. Por eso pide, en clave, al mozo que venda "el entrepiernas por cincuenta; el mete que saca, por cuatro; y el dale que dale, por tres". Estos elementos corresponden respectivamente al caballo, el freno y las espuelas. Para efectos comparativos, conocemos una versión similar recogida recientemente en Chiloé por Juan Bahamonde, aunque está referida a un contexto diferente (de relación marido -esposa; y no de tahúr- mozo): "-Te juihte (fuiste) y vinihte, / entrepiernah qué lo hicihte: / —entrepiernah, cuarenta; / sobraíllo (sobradillo), dieh; / saca y mete, cinco; / y dale que dale, treh" ${ }^{38}$.

En cuanto a otras referencias de este cuentecillo, sólo hay escasas noticias en la compilación de Lenz. Ahí aparece como adivinanza que empieza con la fórmula "Cuatro patas, veinte, etc." y cuya solución es "el caballo". Pero el mismo investigador senala un precedente hispánico que permite confirmar inequívocamente la filiación del texto oral, la versión que documentó Demófilo en la forma dialogada siguiente:

“-En cuánto lo vendiste? / —En cien. / - I el quita i pon? / -En un doblón. / - I el dale que le dé? / —Lo regalé".

La solución debe ser: "el caballo, el freno i el látigo" ${ }^{39}$.

4) El cuento de Los novios que no sabian su nombre desarrolla un motivo de acertijo recíproco entre novio y novia como condición para casarse: adivinar su respectivo nombre. El nombre del novio está cifrado

36 Cfr. S. THOMPSON, op. cit., p. 217.

37 Y. PINO SAAVEDRA, op. cit., t. II, p. 336.

38 Juan BAHAMONDE CANTIN, Las adivinanzas de Chiloé (Teoría y clasificación) (Las Condes-Santiago: Edit. Mar del Plata, 1990), p. 55.

39 R. LENZ, op. cit., II, p. 288. 
en palabras del Credo: "y / nació" = Ignacio; y el de la novia, en una señal física: "flor / en / tina" = Florentina.

Los únicos antecedentes que hemos encontrado de este cuentecillo son los registrados por Lenz, quien aduce también para fines comparativos dos versiones extranjeras, fragmentarias, que rescatan sólo la formulación de uno de los acertijos, una de las versiones registrada en España por Demófilo; y la otra, en Argentina, por Lehmann-Nitsche. La primera dice: "Detrás de una esquina / Hai una tina / Llena de flores; / Si eres discreta / Acierta mi nombre". Y la segunda: "Crece una flor en maceta / Cuyo nombre importa nada / Mas si se trasplanta en tina; / Decidme ¿cómo se llama?" 40.

5) El cuento de El hijo que se enamoró de su madre expresa primero una relación edípica que luego, a instancia de la misma madre, deriva hacia la búsqueda de una mujer parecida a ella. Cuando el joven la encuentra y le requiere el nombre, ella le impone la tarea de descifrarlo en la formulación siguiente: "Si el enamorado / fuera bien fijado / y de buen sentido, / aquí le dejo mi nombre / del color de mi vestido". El resultado es Elena Mora. Y el joven contrae matrimonio con Elena Mora.

También de este cuentecillo sólo encontramos antecedentes en la obra de Lenz, quien agrega a su registro dos versiones fragmentarias de la fórmula central: una procedente de Fernán Caballero y repetida por Demófilo; y la otra, de Lehmann-Nitsche ${ }^{41}$.

6) En el cuento de El rey que tenía tres hijas casaderas, el destinador asigna a un anciano la tarea de criar un piojo. Cuando éste llega a un tamaño desmesurado, le ordena sacarle el cuero y exhibirlo públicamente para que los pretendientes de la princesa puedan adivinar de qué animal es. El anciano es el único que acierta, luego recibe a la princesa como premio y se consuma la boda. Pero él muere pronto y la princesa es conquistada por un príncipe. Una negra obstruye la relación, pero es eliminada fácilmente y la pareja contrae matrimonio. Así la princesa sustituye lo viejo por lo mozo en estas segundas nupcias.

Este cuento es indudablemente una variante del Tipo 621 fijado por Aarne-Thompson. Según el esquema narrativo típico, es la princesa quien "ha alimentado un piojo hasta hacerse tan grande como un becerro, y a su muerte se ha hecho un vestido con su piel. Accede a casarse con el hombre que adivine de qué está hecho el vestido. El héroe lo descubre mediante trucos y así la gana" ${ }^{42}$. Como cuento autónomo, conocido con

\footnotetext{
40 R. LENZ, op. cit., II, p. 297.

41 R. LENZ, op. cit., III, p. 292.

42 S. THOMPSON, op. cit., p. 213.
} 
el nombre de La piel del piojo, se encuentra "aquí y allá, en toda Europa, desde donde ha sido llevado a Indonesia y Filipinas" ${ }^{43}$. Y habría que agregar que también de Europa ha pasado a América y específicamente a Chile. Las otras versiones que aquí se conocen han sido registradas por Lenz, Montenegro, Laval y Pino Saavedra ${ }^{44}$.

7) y 8) Los relatos llamados El rey que tenía un cajón de plata y Grillo, el adivino del rey son versiones de un mismo cuento. En resumen, un rey pone a prueba la competencia de un adivino profesional. Éste debe resolver una situación enigmática: descubrir a los ladrones de un cajón lleno de plata y localizar este tesoro. Mientras está preso, el adivino enfrenta la disyuntiva: recuperar su libertad o morir. Cada criado a su turno debe servirle la comida diariamente. El primer día dice: "Gracias a Dios que tengo uno"; al segundo día, "Gracias a Dios que tengo dos"; y al tercero, "Gracias a Dios que tengo tres". Él se refiere a los días, pero los criados, que son los autores del robo, creen que han sido descubiertos y terminan por confesarle la verdad. Después de este acierto fortuito, el adivino es sometido a una nueva prueba: el rey esconde un grillo en la mano y le pide que adivine qué cosa es la que tiene escondida. Él exclama entonces: "iEn qué apretura te hallas, pobre Grillo!", refiriéndose a sî mismo, pues tal es su nombre. Así, al acertar nuevamente en forma fortuita, recupera su libertad.

Las dos versiones recogidas varían sólo en detalles, pero mantienen una estructura básica cuya filiación no cuesta identificar con el Tipo 1641 del índice internacional, cuento conocido con la denominación común de $E l$ doctor sabelotodo, aunque el nombre del héroe varíe de una versión a otra y pueda ser Cangrejo, Grillo o Rata. Este cuento, según Thompson ${ }^{45}$, es de origen oriental y goza de gran popularidad en toda Europa, Asia, Africa y también es común entre los negros de Jamaica y Georgia y entre los franceses de Luisiana. Tan popular debe ser que el mismo investigador asegura que de él se conocen más de 400 versiones. A ellas habría que agregar las varias versiones registradas en países latinoamericanos que señala Pino Saavedra ${ }^{46} \mathrm{y}$, por supuesto, la versión registrada por este mismo investigador en el norte de nuestro país: Los consejos de "El Grillo" ${ }^{47}$.

43 Ibid., p. 213.

44 Yolando PINo SAAvedra, Cuentos araucanos de Chile (Santiago de Chile: Ediciones de la Universidad de Chile, 1987), pp. 161 y 263.

45 S. THOMPSON, op. cit., p. 200.

46 Y. Pino SAAVEDRA, op. cit., t. II, p. 344.

47 Este cuento lleva el núm. 138 en su colección. Vid. Y. Pino SAavedra, Cuentos folklóricos de Chile, t. II, pp. $264-269$. 
9) En el Cuento con adivinanza un rey propone a los padres de hijas casaderas un enigma cuya solución permita encontrar la mujer para su hijo. El enigma surge de una situación prematrimonial vivida por el príncipe y su pretendida, una muchacha muy humilde. El rey descubre un forado en la habitación del príncipe y, además, ha recibido un bebé oculto en un canasto de flores. De esta situación prematrimonial, el rey elabora una adivinanza o acertijo: "Estaba el palomo un día / arriba en el palomar; / vino la paloma, / lo vino a tantear. / No "lo" vieron salir / ni menos "dentrar" ". Por consejos de la muchacha, responde el padre y completa el sentido de la formulación: "Lo que llevó, / lo mandó a dejar". Todo concluye con la boda entre el príncipe y la pobre mujer.

No hay claridad sobre la filiación de este cuento, pero parece ser una variante de La campesina ingeniosa (Tipo 875), ya que este cuento "siempre comienza indicando cómo el rey logra hacer comparecer a la ingeniosa muchacha ante su presencia" y después de resolver el acertijo (o los acertijos) ésta casa con él ${ }^{48}$. En el cuento local, no se trata de una campesina, pero sí de una muchacha muy pobre y la boda no se realiza con el rey, sino con el hijo del rey, es decir, con el príncipe.

10) y 11) El cuento de Los tres hermanos y la adivinanza para el rey y el Cuento como adivinanza son versiones de un mismo relato. La princesa es ofrecida a quien proponga un enigma o adivinanza que no pueda resolver el rey. Frente a la disyuntiva de vida o muerte, un muchacho desvalido ingenia la formulación de una adivinanza a partir de las situaciones que vive en su trayecto hacia el reino. El rey no puede adivinar $\mathrm{y}$, en consecuencia, el muchacho casa con la princesa.

La clara filiación de este cuento está en el Tipo 851 del índice internacional. Hay algunas leves variantes. En dicha tipificación, es la propia princesa quien se enfrenta a la imposibilidad de descifrar la fórmula, de ahí el nombre propuesto: La princesa que no pudo resolver el acertijo. En las versiones de Osorno, la princesa es ofrecida al pretendiente que proponga una adivinanza que el rey no pueda resolver (siguiendo el esquema del Motivo H 551). Pero la coincidencia fundamental está en que siempre la adivinanza es propuesta sobre la base de experiencias fortuitas (Motivo H 565), aunque la formulación también suele variar bastante de una a otra versión.

Acerca de la la estructura típica del cuento La princesa que no pudo resolver el acertijo, dice Thompson: "En éste, la ofrecen al hombre que pueda proponerle una adivinanza muy difícil para ella. Camino hacia la lucha le dan al héroe una pista que más tarde se convierte en una adi-

48 S. THOMPSON, op. cit., p. 217. 
vinanza. Ve a un caballo envenenado y comido por cuervos, que luego mueren. A los cuervos se los comen doce hombres quienes mueren envenenados. En caso de que el cuento tenga esta introducción, la adivinanza que él propone es "Uno mató a ninguno y, sin embargo, mató a doce" $"{ }^{49}$.

De las versiones orales osorninas, la más completa es la segunda. El protagonista lleva para el viaje hacia la corte una tortilla (una "leuca") que la madre ha envenenado. Ésta desconfiaba tanto de la capacidad de su hijo que prefería que muriera en el trayecto antes que ser decapitado por el rey. Pero el muchacho da la tortilla a su perrita Paula. Ésta muere y comen de ella dos jotes, que luego igualmente mueren. Asa los jotes, pero siete bandidos le arrebatan el asado y también perecen. Atraviesa un puente y ve que la corriente del río arrastra un caballo muerto y que sobre éste van posados tres jotes. Luego con un tiro de escopeta intenta cazar una coneja preñada. El impacto recae en dos crías que salen a luz en el momento de la huida. Ante la carencia de leña para asar la carne de los gazapos, hace fuego con el papel de los libros sagrados que lleva consigo. $\mathrm{Y}$ con base en estas experiencias muy personales elabora un triple acertijo: 1. "Leuca mató a Paula, Paula mató a dos, y dos mató a siete"; 2. "Me fui por lo duro, me encontré en lo blando y encontré un cadáver que tres frailes le iban cantando"; 3 . "Apunté el (al) que vi y maté el que no vi y comí carne recién nacida, con palabras sagradas".

La formulación del triple acertijo (o del acertijo con tres bases) es común también en la narrativa oral peninsular. Según la versión arquetípica del cuento denominado La adivinanza del pastor, tal como la presenta Rodríguez Almodóvar, el héroe, que atraviesa por similares experiencias, propone a la princesa las siguientes partes del acertijo: 1. "Tiré al que vi y maté al que no vi"; 2 . "Comí de lo engendrao, ni nacío ni criao"; 3. "Mi madre mató a la burra y la burra mató a tres. Aciérteme usted lo que es" 50 .

La difusión internacional de este cuento queda verificada con las versiones y explicaciones de varios autores, tales como Lenz, Pino Saavedra, Thompson, Rodríguez Almodóvar, etc. ${ }^{51}$ Acerca de su difusión, Lenz —-basado en la documentación de Grimm-Bolte - señala que este

\footnotetext{
49 S. THOMPSON, op. cit., p. 214.

50 Antonio RODRf́GUEz ALmodóvaR, Los cuentos maravillosos españoles (Barcelona: Crítica, 1982), p. 90.

51 R. LENZ, op. cit., III, pp. 272-280; Y. PINO SAAVEDRA, Cuentos folklóricos de Chile, t. II, pp. 145-148 y 329-331; y Cuentos araucanos de Chile, pp. 193-194; S. THOMPSON, op. cit., pp. 213-214; A. Rodríguez Almodóvar, op. cit., pp. 89-94.
} 
cuento está difundido en más de cuarenta lenguas diferentes; y él mismo da extractos de versiones españolas, portuguesas, brasileñas y otras americanas que sirven para explicar, comparativamente, los fragmentos chilenos que ha recogido ${ }^{52}$. Thompson corrobora la amplia difusión del cuento y se refiere también a su antigüedad: "El tema general de ganar una esposa dando o resolviendo adivinanzas, se remonta a los romances griegos y se repite en las colecciones medievales. Como parte del folklore, el cuento es común desde Islandia y las islas británicas hasta Rusia, y ha sido llevado al extranjero con frecuencia: al Africa central, a Norte y Sudamérica, a través de españoles, portugueses, franceses y colonos negros" ${ }^{53}$.

En las versiones locales aparece añadida una secuencia que con bastante seguridad debe proceder de otro cuento: la parte que se refiere a una nueva exigencia que impone el rey y que aquí tiene las características de un verdadero motivo, identificable como la prueba de los pretendientes. Un príncipe y el muchacho deben dormir con la princesa y, en definitiva, la conquistará aquél que amanezca abrazado con ella. Esta secuencia proviene seguramente del cuento típico que el índice internacional llama Las marcas del nacimiento de la princesa (Tipo 850). Thompson señala que en dicho cuento, como prueba adicional, "la princesa se le entregará al pretendiente a quien ella se vuelva en la noche. El héroe y un rival pretendiente se acuestan con ella. Cada uno hace lo posible por seducirla y finalmente ella se vuelve hacia el héroe" ${ }^{54}$.

\section{Palabras finales. Interpretación Global}

Los relatos aquí analizados revelan que pertenecen a un ciclo bastante definido de cuentos folklóricos cuyo eje vertebral está en el discurso adivinatorio. Tanto las versiones actuales como los ejemplos aducidos del pasado indican la existencia de una unidad estructural subyacente que ha podido mantenerse y que ha permitido generar distintos cuentos de la misma clase, pero singularizados por sus temas, sus personajes, sus acciones, sus formas lingüísticas.

En estos cuentos se privilegia el ingenio para decodificar el mensaje cifrado así como también la habilidad para construirlo. El impostor es el único que fracasa en ese intento, aunque es el único que se autoconsidera adivino de profesión. En cambio, como en otras clases de cuentos, el más

\footnotetext{
52 R. LENZ, op. cit., III, pp. 272-280.

53 S. ThOMPSON, op. cit., p. 214.

54 S. THOMPSON, op. cit., p. 213.
} 
desvalido revela tener fuerza interior suficiente para enfrentar la situación límite, vencer las pruebas de ingenio, y obtener finalmente la recompensa. Tal recompensa se identifica con el objeto deseado. Sólo en algunos de estos cuentos tal objeto deseado es la mano de la princesa y el ascenso al reino, según la axiología del héroe tradicional. En perspectiva histórica y en búsqueda de raíces, algunos autores —como por ejemplo el mismo Propp ${ }^{55}$ - han vinculado toda tarea difícil cumplida por el héroe antes del matrimonio, con antiguos ritos de iniciación y, asimismo, con las necesidades de renovación y sucesión del reinado en muchas sociedades de la antigüedad. Pero en el grupo de cuentos examinados hay otras modalidades que se apartan de esa situación arquetípica y que simplemente son análogas a otras situaciones posibles. Por ejemplo: el objeto deseado puede consistir en la boda de una humilde muchacha con un rey o un príncipe. $\mathrm{Y}$ en otros casos, puede tratarse también del matrimonio de una pareja de igual nivel social y generacional (en que se impone la juventud frente a la vejez), sin afán de ascenso social, sólo con la motivación de consolidar el vínculo amoroso. Otras veces incluso la recompensa puede manifestarse en la recuperación de bienes perdidos; o en otro logro social distinto, cual es el restablecimiento de la libertad.

En muchos de estos cuentos los elementos del mundo narrativo corresponden a configuraciones lejanas en el tiempo y en el espacio. No obstante, en esos mundos se reconocen algunas situaciones análogas a las de la circunstancia inmediata de los narradores. Esto indica que ciertos estereotipos de la vida social del pasado se mantienen y otros naturalmente han cambiado. Así revelan mayor estabilidad los contrastes rico / pobre y sabio / "leso", mientras que la relación social en que contrastan rey / vasallo, o rey / criado, se transfiere parcialmente a la mención contrastiva rey / inquilino. Algo semejante sucede con la relación contrastante princesa / criada negra, que en el mismo cuento tiene su homología en la relación príncipe-patrón / empleada. Al incorporar en la materia narrativa algunos elementos de la vida social circundante, los narradores aproximan hacia la actualidad de su propia circunstancia la temporalidad interna del cuento; sin embargo, no confunden los planos. Por otra parte, algunos elementos del ambiente inmediato también tienen presencia en estos cuentos, lo que produce algún efecto superficial de color local y nada más. $\mathrm{Al}$ respecto, ciertos referentes de la vida campesina parecen inevitables: el coligüe (vegetal regional), la leuca (tortilla), la callana (tostador), el gualato (especie de azadón), o un alimento tan común en el campo sureño

55 Vladimir PROPP, Las raices bistóricas del cuento, trad. de José Martín Arancibia (de la versión italiana) (Madrid: Fundamentos, 1981). 
como es la harina tostada; otras menciones revelan simplemente acomodación de aquello que es poco familiar o menos conocido a lo más común o próximo a la experiencia vital de los narradores; por ejemplo: un retrato deviene en fotografía, los manjares en confites, los cuervos en jotes, etc. Tampoco estas menciones inciden en la estructura profunda de los relatos.

En resumen, los cuentos aquí analizados, como tantos otros cuentos folklóricos, han viajado, han traspasado las barreras idiomáticas, se han trasladado de un país a otro en una cadena constante de actos de habla. A medida que se han desarrollado investigaciones, se ha venido poniendo de manifiesto también la estrecha relación entre los temas y motivos del cuento folklórico y los de la literatura escrita de otras épocas, sin poderse determinar muchas veces cuál fue el primer soporte de su formalización: la página escrita, o sólo la creación verbal retenida y moldeada por la memoria de los narradores. De todas maneras, el hecho de que el cuento folklórico se mantenga en medios alejados de la cultura del libro, indica que la oralidad es un medio poderoso que ha permitdo traer hasta nuestra actualidad antiguos relatos en que el hombre más modesto ha podido proyectar y reconocer sus flaquezas y aspiraciones, sus propias carencias y el afán de superarlas.

\section{CONSTANTINO CONTRERAS}

Universidad de La Frontera, Temuco (Chile)

EDUARDO BARRAZA

Universidad de Los Lagos, Osorno (Chile)

Este artículo está centrado en el estudio de un conjunto de cuentos "de adivinanzas" recopilados de la tradición oral de Osorno (sur de Chile). El análisis comprende dos aspectos: a) la estructura narrativa, en sincronía, y b) su filiación, basada en relaciones intertextuales, en diacronía. Más adelante se presenta el corpus de cuentos folklóricos estudiados y las correspondientes notas lingüísticas aclaratorias de algunas formas dialectales.

The subject of this article is a corpus of riddle tales compiled from the oral tradition of Osorno (southern Chile). The analysis includes two aspects: a) the narrative structure, from a synchronic point of view, and b) their filiation, based on their diachronical intertextual relationships. Further on, the corpus of folk tales is presented accompanied with linguistic notes explaining some dialectal forms. 